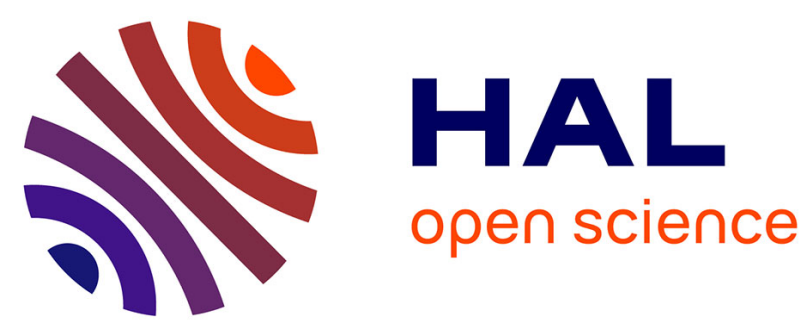

\title{
Complex electrical resistivity and dielectric permittivity responses to dense non-aqueous phase liquids' imbibition and drainage in porous media: a laboratory study
}

\author{
Mohammad Ali Iravani, Jacques Deparis, Hossein Davarzani, Stéfan \\ Colombano, Roger Guérin, Alexis Maineult
}

\section{To cite this version:}

Mohammad Ali Iravani, Jacques Deparis, Hossein Davarzani, Stéfan Colombano, Roger Guérin, et al.. Complex electrical resistivity and dielectric permittivity responses to dense non-aqueous phase liquids' imbibition and drainage in porous media: a laboratory study. Journal of Environmental and Engineering Geophysics, 2020, 25 (4), pp.557-567. 10.32389/JEEG20-050 . hal-03097604

\section{HAL Id: hal-03097604 https://hal.sorbonne-universite.fr/hal-03097604}

Submitted on 5 Jan 2021

HAL is a multi-disciplinary open access archive for the deposit and dissemination of scientific research documents, whether they are published or not. The documents may come from teaching and research institutions in France or abroad, or from public or private research centers.
L'archive ouverte pluridisciplinaire HAL, est destinée au dépôt et à la diffusion de documents scientifiques de niveau recherche, publiés ou non, émanant des établissements d'enseignement et de recherche français ou étrangers, des laboratoires publics ou privés. 


\section{Complex electrical resistivity and dielectric permittivity responses to dense non-aqueous phase liquids' imbibition and drainage in porous media: a laboratory study}

Mohammad Ali Iravani ${ }^{1,2}$, Jacques Deparis ${ }^{1, *}$, Hossein Davarzani ${ }^{1}$, Stéfan Colombano ${ }^{1}$, Roger Guérin ${ }^{2}$, Alexis Maineult ${ }^{2}$

1) BRGM, French Geological Survey, 45060 Orléans, France

2) Sorbonne Université, CNRS, EPHE, UMR 7619 METIS, 75005 Paris, France

Short title: Saturation effects on electrical signatures of DNAPL-saturated media

* Corresponding author. E-mail: j.deparis@brgm.fr

Keywords: Spectral induced polarization (SIP), Time domain reflectometry (TDR), Dense non-aqueous phase liquid (DNAPL), Complex resistivity, dielectric permittivity

Intended for publication in the Journal of Environmental and Engineering Geophysics 


\section{Abstract}

The effective techniques for remediation of sites polluted by dense non-aqueous phase liquids (DNAPLs) remains a challenge. Among the various technical monitoring methods, there is an increasing interest in studying the geophysical characteristics of contaminated soils, as indicators of the progress in clean-up programs. This work sought to investigate the variation of the electrical complex resistivity and the relative permittivity by analyzing the results obtained from spectral induced polarization (SIP) and time domain reflectometry (TDR). Different series of measurements during drainage and imbibition of DNAPLs in porous media were done to validate the clean-up process on sites polluted by DNAPLs. Therefore, a methodology based on laboratory work was designed and carried out to study the electrical complex resistivity (both in magnitude and phase) in the frequency range $0.183 \mathrm{~Hz}$ to $20 \mathrm{kHz}$, and the relative dielectric permittivity at $70 \mathrm{MHz}$. The experiments were done on small 1D cells. In these cells, glass beads were used as a porous medium. Two different fluid couples, i.e. coal $\operatorname{tar}(\mathrm{CT})$ /water and canola oil (CO)/salty ethanol (SE), were used to produce two-phase flow.

Our findings highlight that due to the high resistivity of $\mathrm{CO}$ and $\mathrm{CT}$, an increase in water saturation led to decrease in amplitude and phase. Saturation change of SE had the same effect on resistivity but no relationship was found for phase and saturation for the mixture CO and SE. It is also showed that the complex resistivity and relative permittivity measurements were compatible with generalized Archie's law and complete complex refractive index method (CRIM) model as two empirical models for defining the correlation between the electrical resistivity, relative permittivity, and saturation of each phase in the multiphase porous medium. 


\section{Introduction}

The remediation of dense non-aqueous phase liquids (DNAPLs) in porous media continues to be one of the most challenging problems facing environmental scientists and engineers. DNAPLs are one of the largest sources of soil pollution in the world (Pankow and Cherry, 1996). While it is primarily the responsibility of polluting industries to clean up polluted sites, researchers are left to come up with practical and effective remediation techniques. Among these techniques, various geophysical methods can be used to localize DNAPL plumes and to monitor the effectiveness of remediation processes (Romig, 2000).

Optimal usage of geophysical tools and technology based on the economic considerations is a key point for all practical works. To follow field remediation by geophysics, the behavior of geophysical parameters should be understood, and therefore empirical models known to transform geophysical parameters to saturation will be used to obtain the saturation field concerning to magnitude of each parameter. Compared to field works, laboratory measurements have more resolution due to lower electrode spacing and known initial stage. The transposition of these measurements should be validated in the field study. In the field, the saturation of the coal $\operatorname{tar}(\mathrm{CT})$ in the contaminated soil was decreased by DNAPL recovery with the method of pump and treat. Validating the clean-up process and calculate residual pollutant saturation is the main responsibility of the geophysics in remediation programs. Quantifying of spatial characteristics of physical properties (e.g electrical resistivity and relative permittivity) of the polluted soil needs precise measurements in both laboratory and field. In this study, the suitability of one electro-geophysical method, spectral induced polarization (SIP), for evaluating the resolution and the accuracy of resistivity data and time domain reflectometry (TDR) for obtaining relative permittivity and their potentials for cleanup monitoring were investigated.

SIP might have enough resolution and precision to be suitable for DNAPL detection and 
validating depollution processes in contaminated soils, but it needs to be proven by further electro-geophysical studies in the laboratory and field. Recently, the induced polarization (IP) method has been used to investigate the geophysical characteristics of soils (e.g., Mashhadi and Ramazi, 2018; Revil et al., 2015; Jang et al., 2014; Slater et al., 2014; Attwa and Gunther, 2013; Weller et al., 2010; Candansayar, 2008; Braga et al., 1999). Many laboratory studies have discussed the effects of saturation changes on IP responses (e.g., Maineult et al., 2018; Schmutz et al., 2012; Breede et al., 2011; Jougnot et al., 2010; Cosenza et al., 2007; Titov et al., 2004), evidencing saturation having a strong influence on complex resistivity spectra.

Several studies have documented the potential of using geophysical methods to monitor cleanup at both field and laboratory scales (e.g., Cardarelli and Di Filippo, 2009; Hwang et al., 2008; Snieder et al., 2007; Sogade et al., 2006; Brewster and Annan, 1994). Among various geophysical approaches, electrical methods have proven their potential to characterize subsurface changes (e.g., Gharibi and Bentley, 2005; Binley et al., 2005). They have been used to investigate geophysical properties of soils in a wide range of environmental applications (e.g., Grimm and Olhoeft, 2004; Briggs et al., 2004), especially within shallow soils (e.g., Romig, 2000) and porous rock (e.g., Kaselow and Shapiro, 2004). Some previous studies focused on detecting light non-aqueous phase liquids (LNAPLs) detection (e.g., Atekwana et al., 2000). In this study, we focus specifically on DNAPLs. Spherical-glass beads (GB) were used as a porous medium and various conductive fluids - canola oil (CO), salty ethanol (SE), water, and CT - were used as liquid phases.

Electrical charge transport and separation in a porous medium are referred to as electrical conduction and polarization, respectively. A saturated porous medium is made of two components, a solid phase (porous matrix) and pores that are filled with fluids. The in-phase electrical conduction of the medium is generally due to the electrical conductivity of the solution inside the pores. Nevertheless, interfacial conduction (in the case of a high specific 
surface area, for instance when the medium contains clays) on grain surfaces can lead to polarization phenomena and out-phasing components in the conductivity (Kemna et al., 2000). In the absence of electrode polarization (Tsonos, 2019), the complex resistivity consists of two terms, described by $\rho=\rho^{\prime}+i \rho^{\prime \prime}$ where $\rho^{\prime}(f)$ and $\rho^{\prime \prime}(f)$ are respectively the real and imaginary parts as a function of frequency $f$, with $i^{2}=-1$. The magnitude $|\rho|$ and the phase $\varphi$ of the complex resistivity can be obtained from Eq. (1) and (2):

$$
\begin{gathered}
|\rho|=\sqrt{\left(\rho^{\prime 2}+\rho^{\prime \prime 2}\right)}, \\
\varphi=\tan ^{-1}\left(\frac{\rho^{\prime \prime}}{\rho^{\prime}}\right) .
\end{gathered}
$$

The units of phase and magnitude of complex resistivity are radian and $\Omega . m$, respectively. The phase shift is mainly related to the grain size, to the specific surface area (Börner and Schön, 1991), and the pore space shape. For instance, the larger the grain size, the smaller the frequency of the peak of the phase. It means that phase lag in a sandy medium is less than the lag in silty and loamy media (Kemna et al., 2000).

The relative permittivity $\left(\varepsilon_{r}\right)$, also named dielectric constant, is a physical parameter that describes quantitatively the electrostatic characteristics of particles of a medium under immersed charge (current) and resulting electric field (Archer and Wang, 1990). Relative permittivity is the ratio of absolute permittivity $(\varepsilon)$ and permittivity of vacuum $\left(\varepsilon_{0}\right)$ expressed by Eq. (3):

$$
\varepsilon_{r}=\frac{\varepsilon}{\varepsilon_{0}}
$$

The relative permittivity is a frequency dependent complex value, $\varepsilon(f)=\varepsilon^{\prime}(f)+i \varepsilon^{\prime \prime}(f)$ where $\varepsilon^{\prime}(f)$ is the real part and $\varepsilon^{\prime \prime}(f)$ is the imaginary part. As was illustrated in a previous study (Iravani et al., 2020), for two-phase fluid saturation in a porous medium made of GB, relative permittivity is a frequency- and temperature-dependent parameter.

In this paper, the effects of two-phase flow (DNAPL saturation change) on complex 
resistivity and dielectric permittivity are studied. A series of laboratory experiments were performed to characterize the electrical response to saturation changes. Small 1D cells were initially filled with water or SE and GB and were subjected to a vertical CT or CO injection to apply imbibition and drainage tests. The similarity in hydraulic and geophysical properties of $\mathrm{CO}$ with $\mathrm{CT}$ encouraged us to carry out another experiment with $\mathrm{CO}$ in parallel. Before starting experiments, water was used as the reference liquid to evaluate the electrodes, which measured the electrical potential. Originally, the experiments were performed using CT and water. Due to the specific physical and chemical characteristics of $\mathrm{CT}$, it was decided to use a less complex fluid compared to CT with hydraulic and geophysical characteristics close to this DNAPL to perform another set of experiments. $\mathrm{CO}$, which has hydraulic and electrical properties similar to $\mathrm{CT}$, might have been the best option but it is lighter than water. The challenge was finding a fluid lighter than $\mathrm{CO}$ but with similar characteristics to water. The optimum option was ethanol, which is considered a non-conductor fluid with null electrical conductivity (Rocha and SimõesMoreira, 2005), but similar to water. As long as there are no ions in a fluid, the current cannot pass through it. Consequently, other chemicals that conduct electricity like salt $(\mathrm{NaCl})$ must be added to ethanol to increase its electrical conductivity. We then applied mixing models to explain the observed responses.

\section{Experimental setup}

The laboratory program was designed and carried out in line with methods and procedures defined in previous studies by Colombano et al., (2017, 2020), Philippe et al., (2020) and Iravani et al., (2020) in order to be able to monitor the effects of saturation changes on the electrical complex resistivity and the relative permittivity. To achieve this, two cylindrical cells were used (Fig. 1). Both cells have an internal diameter of $5.8 \mathrm{~cm}$ and at a length of $5.56 \mathrm{~cm}$. Cells were manufactured using a thermoplastic non-reactive polymer called polyvinylidene fluoride (PVDF) to prevent potential reactions between strong resistant liquids like CT and the 
test setup (Schweitzer, 2004). PVDF is a nontoxic material with no impact on liquid or solid phases of the sample. PVDF also has a high temperature refractory $\left(-40\right.$ to $\left.120^{\circ} \mathrm{C}\right)$. Its low air and gas permeability and high electrical isolation and dielectric constant made this polymer suitable to be used in the setup (Schweitzer, 2004).

The cells were filled with a non-consolidated, highly permeable porous medium with $40 \%$ porosity, namely $1 \mathrm{~mm}$ diameter GBs. There were several reasons behind the application of GB instead of soil samples. The first reason is taking advantage of the transparency of GB to better monitor and report $\mathrm{CT}$ and $\mathrm{CO}$ levels in the samples to calculate water/SE and $\mathrm{CT} / \mathrm{CO}$ saturations. The use of GB also prevents the occurrence of unexpected phenomena such as adsorption during the experiment. The relative permittivity of a GB pack is 5.9 (Orlando and Palladini, 2019). The complex resistivity of the medium was measured with SIP using SIP-lab IV manufactured by Radic Research in Germany. The complex resistivity was measured over a broad frequency range $(0.183 \mathrm{~Hz}$ to, $20 \mathrm{kHz})$ with an incremental coefficient of 2 , according to SIP-lab IV apparatus properties. The relative permittivity was measured with TDR probes (model 5TE, METER Group) with dimensions of $10 \mathrm{~cm} \times 3.2 \mathrm{~cm}$ (with $2.5 \mathrm{~cm}$ space between the first and the third branch, Fig. 1a). The influence of the TDR probe on the experiment is weak because (1) the volume ration between the probe $\left(3 * 2.5 \mathrm{~cm}^{3}\right.$ and cell is around $5 \%,(2)$ the flow is in the creeping flow regime (Reynolds number equal to 3.7). In addition, we performed resistivity measurement with and without TDR probe during white test (i.e. column filled with water). The resistivity relative difference is less than $1 \%$, which is negligible compared to the experimental error.

TDRs were connected to a Campbell CR-1000 data logger. For these probes, the measurement frequency was $70 \mathrm{MHz}$. This frequency was chosen to reduce salinity and textural effects of the medium compared to low frequencies (Kizito et al., 2008). For the SE solution, taking into account the solubility of salt in ethanol at $25^{\circ} \mathrm{C}, 0.65 \mathrm{~g}$ of $\mathrm{NaCl}$ was mixed with $1 \mathrm{~kg}$ 
of ethanol (Burgess, 1978). The resulting conductivity was $0.0251 \mathrm{~S} \mathrm{~m}^{-1}$ at, $20^{\circ} \mathrm{C}$ which is less than the conductivity of tap water $\left(0.0345 \mathrm{~S} \mathrm{~m}^{-1}\right)$ at the same temperature but sufficient to be used in the experiments. Liquid $(\mathrm{CT} /$ water and $\mathrm{CO} / \mathrm{SE})$ saturations were supposed to be variable parameters in our experiments.

Each cell and column was equipped with a small tap at the bottom to control the introduction of water/SE to samples by a peristaltic pump (Watson Marlow 530U). Degassed tap water, prepared in an ultrasound tank (VWR Ultrasonic Cleaner - USC500D), was used in this experiment. Degassed water was used to prevent air bubbles forming in samples. There were two holes at the top and the bottom of the main sample for introducing and draining fluids (water/SE and CT/CO). The sample was connected to two graded reservoirs with an internal diameter of $3.5 \mathrm{~cm}$ and a height of $36 \mathrm{~cm}$. Two PVDF filters were used at the top and the bottom of each sample to keep the GB (porous media) inside cells/columns. The schemas of a vertical cross-section of a cell and an experimental setup are shown in Fig. 1. In Fig. 1b, the right and the left reservoirs are for water/SE and $\mathrm{CT} / \mathrm{CO}$, respectively. Both reservoirs were connected to samples using flexible plastic tubes. The water/SE reservoir was placed and fixed at the top of the sample, while the $\mathrm{CT} / \mathrm{CO}$ reservoir can move vertically.

$\mathrm{AC}$ current was injected using two ring metallic electrodes A and B (made of nickel-cobalt alloy (MP35N)), exactly at the top and the bottom of the sample. The voltage response of the medium was measured using non-polarizable potential electrodes, which were inserted in a row with a spacing of $1.85 \mathrm{~cm}$ in pre-drilled holes. These hand-made $\mathrm{Cu} / \mathrm{CuSO}_{4}$ potential electrodes (after Maineult et al., 2004) were made of $72.75 \%$ milli-Q water (ultrapure water), $26 \% \mathrm{CuSO}_{4}$, and $1.25 \%$ gelatin. A heating shaker was used to mix the solution at $80^{\circ} \mathrm{C}$ for approximately one hour. Wenner- $\alpha$ array was chosen with distance $A B=M N=A M=A N$ equal to $1.85 \mathrm{~cm}$.

Knowing the conductivity of the tap water at the beginning of each experiment (measured with a portable conductivity meter model pH/Cond 340i (WTW Measurement System Inc.)) 
made it possible to compute geometric factors for the cells to obtain the resistivity from the measured impedance of the medium when the cell was filled with water. The value of the geometric factor was then used throughout the experiment to transform resistance into resistivity.

To examine the stability of the copper sulfate electrodes, the same measurement was carried out at the end of the experiment (i.e. cell fill with tap water). Samples were drained and imbibed by gradually raising or lowering the DNAPL (or CO) reservoir, at the rate of $2 \mathrm{~cm}$ per 3 hours to prevent air trapping in the medium, in two series of drainage-imbibition cycles. In a given cell, two cycles per experiment were usually performed in two weeks. We used two cells: one for $\mathrm{CT} /$ water and the other for $\mathrm{CO} / \mathrm{SE}$. Experiments were performed in an oven at a temperature of, $20^{\circ} \mathrm{C}$. The dielectric relative permittivity and the electrical complex resistivity were recorded at a rate of one spectrum every $30 \mathrm{~s}$ and 2 hours, respectively. After balancing the level of $\mathrm{CT} / \mathrm{CO}$ in the left reservoir with the water/SE level in the reservoir at the top of the sample to reach equilibrium and to prevent $\mathrm{CT} / \mathrm{CO}$ from entering the bottom of the sample, experiments were started. The volume and height of $\mathrm{CT} / \mathrm{CO}$ and water/SE added to the system were documented precisely. Each time before changing CT/CO reservoir level $(2 \mathrm{~cm})$, the water/SE and $\mathrm{CT} / \mathrm{CO}$ levels were carefully monitored to calculate the drained or injected volume. The volume and the porosity of the samples were determined before starting the experiments. The porosity of the cells was calculated by subtracting the volume of GBs from the total cell volume over the total volume of the cell. Therefore, the saturation could be determined simply by measuring the volume changes. Drainage was finished when the CT/CO was observed in water/SE reservoir and imbibition was finished when water/SE was observed in the linking tube between the sample and $\mathrm{CT} / \mathrm{CO}$ reservoir.

This laboratory setup was designed to assess the effects of saturation changes in saturated multiphase media. Having high reliability for three saturation points is very important for each 
cycle:

- The starting point of the experiment, i.e. when the first cycle of drainage and imbibition is going to start. At this point water/SE saturation is $100 \%$;

to, $20 \mathrm{kHz}$ ) but due to electromagnetic coupling, measurements at frequencies larger than

$10 \mathrm{kHz}$ were not considered. The results are shown in Fig. 2. As mentioned in the experimental setup description, two cycles of drainage and imbibition were performed. The phase variations or SE saturation decreased the amplitude of the resistivity. This occurred because CT and CO are significantly more resistive than water and SE. Resistivity at frequencies between 0.183 to $1000 \mathrm{~Hz}$ was almost constant and at the higher frequency (more than $187.5 \mathrm{~Hz}$ ) was increasing. 
$5.859 \mathrm{~Hz}$ ). For CT and water, the variation of the phase spectrum at low frequencies was less compared to higher frequencies. In addition, the bell shape part of the phase spectrum was shifted to higher frequencies with increasing water saturation. The changes in amplitude and phase variations are in agreement with the behaviors reported by Maineult et al. (2018) from numerical simulation of drainage and imbibition in pore networks.

There was no systematic relationship between the error bars measured by SIP for different frequencies, but the measurement errors for the phase were larger for the $\mathrm{CO} / \mathrm{SE}$ case than for $\mathrm{CT} /$ water. In Fig. 2c, for the measurement with SE saturation $\left(S_{e}\right)$ equal to $4.5 \%$, error bars were larger than for other measurements because of the decreasing volume of conductive SE in the cell. In Fig. 2c, error bars significantly decrease at a higher frequency which is a different behavior compared to $\mathrm{CT} /$ water column results (Fig. 2a). All resistivity measurements in the frequency domain of $\mathrm{CO} / \mathrm{SE}$ were selected from the first SE drainage. Except for $S_{e}=28.6 \%$ with a different variation trend, all the other measurements have almost the same trend of variations. Time series for the amplitude of the resistivity and the phase at the frequency of $1.46 \mathrm{~Hz}$ (the frequency close to the field measurements) are shown in Fig. 3. Note that the phase in the second cycle of the $\mathrm{CT} /$ water experiment is negative, but we have no explanation.

\subsection{Effect of saturation on relative permittivity}

The relative permittivity variations as a function of water and SE saturation are shown in Fig. 4. The variation was measured for five different saturation stages for both experiments. The results showed that an increase in water and SE saturation triggers an increase in the relative permittivity in both cases. According to our last study (Iravani et al., 2020), at higher water saturation, due to higher relative permittivity of water compared to CT, an increase in relative permittivity was expected. Results during imbibition support the idea that increasing water/SE saturation increases measured relative permittivity. 


\subsection{Empirical models for the amplitude of the resistivity}

Since the electrical conductivity $\sigma(\rho=1 / \sigma)$ depends on the geometry and topology of the porous medium, many studies (e.g., Glover, 2010; Glover et al., 2000; Schilling et al., 1997; Guéguen and Palciauskas, 1994; Luo, Wood, and Cathles, 1994; Somerton, 1992; Bussian, 1983; Korvin, 1982; Hashin and Shtrikman, 1962; Archie, 1942; Lichtenecker and Rother,

1931) have been carried out to investigate the relationship between the bulk electric conductivity of the medium and fluid saturation. Some models work with a maximum of two conductive phases (e.g., Schilling et al., 1997; Waff, 1974; Hashin and Shtrikman, 1962) while some have the option of applying multiple phases (e.g., Parallel model used by Guéguen and Palciauskas, 1994; Luo et al., 1994; Somerton, 1992). The very classical and often used Archie's law (1942) was defined for only one phase. Some proposed models are with (e.g., generalized Archie's law and Bussian equation) and some without (e.g., Random model by Guéguen and Palciauskas, 1994) variable exponents. For instance, $m$ in generalized Archie's law is the variable exponent that we found for each phase by the least mean square (LMS) method.

The most investigated simple model to study the relationship between the bulk conductivity, its porosity, and fluid conductivity, when the porous media is nonconductive (Glover, 2010), is the classical Archie's law (1942, Eq. (4)):

$$
\sigma=\sigma_{\text {fluid }} \varphi^{m}
$$

where $\sigma_{\text {fluid }}\left(\mathrm{S} \mathrm{m}^{-1}\right)$ is the conductivity of the liquid inside the pores, $\varphi(-)$ is the porosity, and $m$ is the cementation exponent. One of the advantages of Archie's law compared to many mixing models is that it has a variable component $(m)$ that makes this model applicable in many cases. A more recent model called generalized Archie's law was a derivative of traditional Archie's law (e.g., Glover, 2010). In the last decade, generalized Archie's law has been used in many 
where

$$
m_{j}=\frac{\log \left(1-\sum \varphi_{i}^{m_{i}}\right)}{\log \left(1-\sum \varphi_{i}\right)} \quad i \neq j
$$

studies (Glover, 2010; Tiab and Donaldson, 2004; Mendelson and Cohen, 1982; Sen et al., 1981) to investigate the relationship between the bulk conductivity of the porous medium, its porosity and the conductivity of the liquids in pores. The generalized Archie's law for $n$ phases is given by Eq. (5) and (6):

$$
\sigma=\sum_{i=1}^{n} \sigma_{i} \varphi_{i}^{m_{i}}
$$

In these equations, the summation of all fractions should equal to one (for $\mathrm{n}$ phases, $\left.\sum_{i=1}^{n} \varphi_{i}=1\right)$

In a saturated porous medium $\varphi_{1}+\varphi_{2}+\ldots+\varphi_{n-1}=\varphi^{*}$ with $\varphi^{*}$ the total porosity. In the interpretation of saturation exponents of generalized Archie's law, water/fluids contents should be used instead of water/fluids saturations. For instance, if the fluid is water, the relationship between water content $\left(\theta_{w}\right)$ and water saturation $\left(S_{w}\right)$ is $\theta_{w}=S_{w} \varphi$.

The generalized Archie's law (Eq. (5)) for our experimental setups can be expanded as (Eq. (7)):

$$
\sigma_{\text {mixed }}=\sigma_{\text {fluid } 1} \theta_{\text {fluid } 1}{ }^{m_{1}}+\sigma_{\text {fluid } 2}\left(\varphi-\theta_{\text {fluid } 1}\right)^{m_{2}}+\sigma_{G B}(1-\varphi)^{m_{3}},
$$

The conductivity values of water, SE, CT, and CO are $0.0345,0.251,10^{-9}$ (reported by Iravani et al., 2020), and $10^{-11} \mathrm{~S} \mathrm{~m}^{-1}$ respectively. The electrical conductivity of GB was determined between $10^{-11}$ to $10^{-15} \mathrm{~S} \mathrm{~m}^{-1}$ by Griffiths (1999) and we chose $10^{-14} \mathrm{~S} \mathrm{~m}^{-1}$. Due to the low conductivity of CT and GB, the second and third parts of the Eq. (7) are almost negligible. Coefficients $m_{1}, m_{2}$, and $m_{3}$ were calculated by the least square method. As mentioned before, the porosity is $40 \%$, therefore, the solid fraction will be $60 \%$. According to these characteristics, generalized Archie's law equations for both cells are (Eq. (8) and (9), respectively): 


$$
\begin{aligned}
& \mathrm{CT}+\text { water: } \sigma_{\text {mixed }}=0.0345 \theta_{w}{ }^{1.3}+10^{-9}\left(0.4-\theta_{w}\right)^{1.64}+10^{-14}(0.6)^{2.34} \\
& \mathrm{CO}+\mathrm{SE}: \sigma_{\text {mixed }}=0.0251 \theta_{e}{ }^{2.01}+10^{-11}\left(0.4-\theta_{e}\right)^{0.36}+10^{-14}(0.6)^{1.23}
\end{aligned}
$$

According to our results, at the frequency of $1.46 \mathrm{~Hz}$ (see Fig. 5a,b), generalized Archie's law fits rather well to experimental data of resistivity in both cells $\left(\mathrm{CT} /\right.$ water with $\mathrm{R}^{2}=0.9845$ and $\mathrm{CO} / \mathrm{SE}$ with $\left.\mathrm{R}^{2}=0.9996\right)$. After analyzing data, we found that the $\mathrm{CT}$ we used for this study has almost $10-15 \%$ of water inside. It became obvious when we left the bottle of pure CT for a month and surprisingly found that a layer of water appeared at the top of the CT inside the bottle. The other clue was that the measured resistivity of the medium saturated with $100 \% \mathrm{CT}$ was less compared to the true resistivity of CT and GB. Assuming CT conductivity equals $10^{-}$ ${ }^{3} \mathrm{~S} \mathrm{~m}^{-1}$, better experimental data fitting (with $\mathrm{R}^{2}=0.9945$ ) was obtained and the new equation of generalized Archie's law for CT/water is (Eq. (10)):

$$
\sigma_{\text {mixed }}=0.0345 \theta_{w}^{1.8}+10^{-3}\left(0.4-\theta_{w}\right)^{5.2}+10^{-14}(0.6)^{2.34} \text {. }
$$

As shown in Fig. 2, the evolution of phase is regular for $\mathrm{CT}+$ water compared to the $\mathrm{CO} / \mathrm{SE}$ cell where the phase variation was quite chaotic. This phenomenon can be attributed to the extremely high CO resistivity. In the CT/water cell, the "-phase" increased after injecting CT. In Fig. 6 for CT/water, a linear fitting equation was suggested for experimental data of phase at frequency $1.46 \mathrm{~Hz}$ :

$$
- \text { Phase }(\mathrm{mrad})=-0.3811 S w+45.21
$$

This linear equation gives us a good fitting with the coefficient of determination of $\mathrm{R}^{2}=0.96$. The phase variation for different $\mathrm{CO}$ and SE saturations was not investigated in this work due to its irregular behavior. For instance, in Fig. 2d, the phase variation as a function of SE saturation at $1.46 \mathrm{~Hz}$ is oscillating and for each saturation, the variation is different. When $S_{e}=100 \%$, and there is no CO inside the medium, the curve has a trend of variation like any conductive fluids like water with minimum error and the peak point at $187.5 \mathrm{~Hz}$. In this figure, the maximum measurement error recorded at the minimum SE saturation $\left(S_{e}=4.5 \%\right)$ is what we 
expected: the higher the $\mathrm{CO}$ saturation, the higher the measurement error.

\subsection{Empirical models of relative permittivity}

Some previous research focused on the mutual effects of fluid saturation and dielectric properties of a mixture (e.g., Carcione et al., 2003) for a saturated soil with non-aqueous phase liquid (NAPL) and Santamarina and Fam (1997) for a contaminated soil with organic contaminations (like benzene, xylene, toluene, tetrachloroethylene, trichloroethylene, and chlorobenzene). Endres and Knight (1991) investigated the influence of fluid distribution on the relative permittivity at the pore-scale, on a semi-saturated medium with a simple mixing model. Endres and Redman (1993) have also presented a mixing model for contaminated soil. They found that geometry and choice of the wetting phase could strongly affect the fluid distribution and its relation to the dielectric properties of the medium. The complex refractive index technique as a volumetric mixing model has also been used to interpret the dielectric characteristics of a medium (Birchak et al., 1974). Persson and Berndtsson (2002) used a method to investigate the relation between the dielectric constant of a medium partially saturated with sunflower seed oil. They carried out their measurement with TDR, which their method can use for a saturated and partially saturated sandy porous medium. They validated a simple model similar to the complete-refractive index method (CRIM) model. Lack of consensus among the scientific communities in this subject led us to perform this study. (e.g., Endres and Knight, 1992; Rodriguez and Abreu, 1990; Roth et al., 1990 and Wharton et al., 1980), is one of the mixing models that does not have any geometry dependency. CRIM is a simplified form of the Lichtnecker-Rother model (see in Mavko et al., 1998; Guéguen and Palciauskas, 1994) that simply uses one layer at ray limits and complex composites (AjoFranklin et al., 2004). The general CRIM equation is given by (Birchak et al., 1974; Roth et al., 1990; Endres and Knight, 1992): 


$$
\varepsilon^{*}=\left[\sum_{i=1}^{N} v_{i} \varepsilon_{i}^{\alpha}\right]^{1 / \alpha}
$$

334

where $\varepsilon^{*}$ is the permittivity of the mixture, $\varepsilon_{i}$ is the permittivity of the $i^{\text {th }}$ phase, $v_{i}$ is the volume of the $i^{\text {th }}$ phase and $\alpha$ is the empirical constant related to the geometry of the grains and their spatial distribution.

With the hypothesis of $\alpha$ equals 0.5 for a three-phase system (Ajo-Franklin et al., 2004), the CRIM equation for a mixture of air, water, and solid phase is defined as (Rodriguez and Abreu, 1990):

$$
\sqrt{\varepsilon^{*}}=S_{w} \varphi \sqrt{\varepsilon_{w}^{*}}+\left(1-S_{w}\right) \varphi \sqrt{\varepsilon_{a}}+(1-\varphi) \sqrt{\varepsilon_{g}},
$$

where $\varepsilon^{*}, \varepsilon_{w}{ }^{*}, \varepsilon_{a}$, and $\varepsilon_{g}$ are respectively relative permittivity of saturated porous media, water, air, and solid phase, $S_{w}$ is the water saturation and $\varphi$ is the porosity.

Eq. (13) is a general form of the CRIM model for a multiphase porous media with two liquids. This equation for experimental setups of this study can be described by:

$$
\varepsilon^{*}=\left(\theta_{w} \sqrt{\varepsilon_{w}^{*}}+\theta_{D N A P L} \sqrt{\varepsilon_{D N A P L}}+(1-\varphi) \sqrt{\varepsilon_{G B}}\right)^{2},
$$

where $\varepsilon_{D N A P L}$ is the relative permittivity of DNAPL, $\varepsilon_{G B}$ is the relative permittivity of GB, $\theta_{w}$, and $\theta_{D N A P L}$ are water and DNAPL contents, respectively. Fig. 4 shows how the relative permittivity changed as a function of water saturation. The CRIM model has a good fit with experimental data in both cases but for $\mathrm{CO} / \mathrm{SE}$ an underestimation of the CRIM model with the same slope as the experimental setup is observed. Contrary to a previous study (Iravani et al., 2020), experimental data of relative permittivity were not normalized here due to uncertainty of the normalizing method, especially in higher temperatures. The relative permittivity of water, $\mathrm{SE}$, and $\mathrm{CO}$ were measured in the laboratory (with the error less than $\pm 1 \%$ ) and the relative permittivity of GB proposed by Louge and Opie (1990) was used to obtain CRIM equations for each setup.

$$
\mathrm{CT}+\text { water: } \varepsilon_{\text {mixed }}=\left(\varphi_{\text {water }} \sqrt{42.7}+\varphi_{C T} \sqrt{6.73}+(1-0.4) \sqrt{5.95}\right)^{2} \text {, }
$$




$$
\mathrm{CO}+\mathrm{SE}: \varepsilon_{\text {mixed }}=\left(\varphi_{\text {ethanol }} \sqrt{34.5}+\varphi_{\text {oil }} \sqrt{3.1}+(1-0.4) \sqrt{5.95}\right)^{2}
$$

Fig. 4 shows that drainage in both saturated porous media decreased the relative permittivity because of the decreasing water/SE saturation that is due to greater relative permittivity of water/SE than $\mathrm{CT} / \mathrm{CO}$. During imbibition, because of replacing $\mathrm{CO}$ and $\mathrm{CT}$ in the porous media, the relative permittivity values increased.

\subsection{About the second cycle}

Laboratory measurements of the complex resistivity show that the first drainage and imbibition cycle follow some empirical models (see above). Change during the second cycle was disordered compared to the first cycle for $\mathrm{CT}+$ water. Because of hysteresis, since the curves of the capillary pressure and saturation for each drainage and imbibition for both cycles are different and our experimental data show different curves for each cycle due to hysteresis phenomena, that may justify these rather "unexpected" data for the second cycle. The other hypothesis for this phenomenon is mistakes in the saturation calculation after the first imbibition. After the first drainage and imbibition cycle, the only indicator for us to stop the imbibition was observing water/SE in the tube connected to the bottom of the cell. For all experiments, we considered the volume in the tube, but maybe the mixing of fluids in this tube or human errors in reporting this volume caused this mismatching. We believe that the precision and accuracy of our measurements are directly related to the existence of water (as a conductive fluid) in the porous media. Not all DNAPL can be removed from porous media after the first imbibition; therefore, that could be the reason for these electro-geophysical data in the second cycle.

In the first cycle, the phase does not show a well-defined variation trend for the $\mathrm{CO} / \mathrm{SE}$ experiment, but a linear correlation was observed for phase variation in the CT/water cell. For $\mathrm{CT} /$ water, phase and water saturation had an inverse relationship demonstrating that decreasing water saturation led to increased phase. At higher frequency, the peak part of the phase spectra 
moved to a lower frequency due to increased CT saturation.

\section{Conclusion}

We studied how complex resistivity and dielectric permittivity varied in two series of experiments in a GB pack saturated with $\mathrm{CT} /$ water and $\mathrm{CO} / \mathrm{SE}$. Results showed that SIP and TDRs are practical methods and tools to measure the electrical complex resistivity and relative permittivity of a saturated porous medium contaminated with $\mathrm{CT}$ and $\mathrm{CO}$ as a function of fluid saturation. The evolution of the magnitude of the complex resistivity with saturation obeys the generalized Archie's law. Observations showed that resistivity increased as water/SE saturations decreased. For the experiment with $\mathrm{CT}$ and water, we observed a linear relationship between -phase and water saturation in accordance with the literature. The -phase value decreased when the water saturation increased.

Increasing in water and SE saturations caused an increase in the relative permittivity that confirms the direct relationship between water/SE saturation and the relative permittivity of a multiphase porous medium. According to these findings, the relative permittivity decreases and increases during drainage and imbibition in a cycle, respectively. Like what we found for the resistivity, the relative permittivity also obeys the CRIM model. The effects of chemical interaction between contaminants and soil grains cannot be neglected in field conditions. This means that extrapolating results obtained using GBs to the actual site remains an issue. Moreover, the question of the upscaling of laboratory results to field scales is still open (i.e. effect of resolution and detection power).

The correlations between saturation and permittivity and electrical complex resistivity could serve as calibration relationship to interpret measurements at the field scale. It is worth mentioning that the application of the laboratory results in the field surveys always has some limitations. In the field experiments with extraneous variables/parameters, it is not easy to avoid any external impact (i.e. temperature effect on resistivity,) on the measurement results. For 
403 instance, laboratory measurement highlight that is possible to compute residual saturation from

404 resistivity and permittivity provided that the initial state is known but this is rarely the case in 405 the field.

406

407 Acknowledgments

408 This study was performed within the BIOXYVAL project. The authors would like to 409 thank ADEME for funding part of the project under the "Investissements d'Avenir" program, 410 BRGM, "Hegmatan-Mahar Ab" the Iranian consulting engineers, for providing the Ph.D. thesis 411 scholarship of Mohammad Ali Iravani, and the valuable experimental assistance of Nicolas 412 Philippe from BRGM and Dr. Said Iravani for his support and encouragement. Finally, we 413 gratefully acknowledge the financial support provided to the PIVOTS project by the "Région 414 Centre - Val de Loire" and the European Regional Development Fund.

415

416 We also declare no conflict of interest.

417

418 Data are partly available on demand. 
Ajo-Franklin J.B., Geller J.T. and Harris J.M., 2004, The dielectric properties of granular media saturated with DNAPL/water mixtures: Geophysical Research Letters, 31(17), L17501.

Archer D.G. and Wang P., 1990, The dielectric constant of water and Debye-Hückel limiting law slopes: Journal of Physical and Chemical Reference Data, 19(2), 371-411.

Archie G.E., 1942, The electrical resistivity $\log$ as an aid in determining some reservoir characteristics: Transactions of the American Institute of Mechanical Engineers, 146, 5467.

Atekwana E.A., Sauck W.A. and Werkema Jr D, .D., 2000 Investigations of geoelectrical signatures at a hydrocarbon contaminated site: Journal of Applied Geophysics, 44(2-3), $167-180$.

Attwa M. and Gunther T., 2013, Spectral induced polarization measurements for predicting the hydraulic conductivity in sandy aquifers: Hydrology and Earth System Sciences, 17(10), $4079-4094$.

Binley A., Slater L.D., Fukes M. and Cassiani G., 2005, Relationship between spectral induced polarization and hydraulic properties of saturated and unsaturated sandstone: Water resources research, 41(12), W12417.

Birchak J.R., Gardner C.G., Hipp J.E. and Victor J.M., 1974, High dielectric constant microwave probes for sensing soil moisture: Proceedings of the IEEE, 62(1), 93-98.

Börner F.D. and Schön J.H., 1991, A relation between the quadrature component of electrical conductivity and the specific surface area of sedimentary rocks: The Log Analyst, 32(5), 612-613.

Braga, A.C., Malagutti F., W., Dourado, J.C. and Chang, H.K., 1999, Correlation of electrical 
resistivity and induced polarization data with geotechnical survey standard penetration test measurements: Journal of Environmental and Engineering Geophysics, 4(2), 123-130.

Breede K., Kemna A., Esser O., Zimmermann E., Vereecken H. and Huisman J.A., 2011, Joint measurement setup for determining spectral induced polarization and soil hydraulic properties: Vadose Zone Journal, 10, 716-726.

Brewster M.L. and Annan A.P., 1994, Ground-penetrating radar monitoring of a controlled DNAPL release:, $200 \mathrm{MHz}$ radar: Geophysics, 59(8), 1211-1221.

Briggs V., Sogade J., Minsley B.J., Lambert M., Reppert P., Coles D., Rossabi J., Riha B., Shi W. and Morgan F.D., 2004, Mapping of TCE and PCE contaminant plumes using a 3-D induced polarization borehole data: Symposium on the Application of Geophysics to Engineering and Environmental Problems (SAGEEP), Environmental and Engineering Geophysical Society, 472-483.

Burgess J., 1978, Metal Ions in Solution. New York, Ellis Horwood.

Bussian, A. E., 1983, Electrical conductance in a porous media: Geophysics, 48(9), 1258-1268.

Candansayar, M.E., 2008, Two-dimensional individual and joint inversion of three-and fourelectrode array dc resistivity data: Journal of Geophysics and Engineering, 5(3), 290-300.

Carcione J., Seriani G. and Gei D., 2003, Acoustic and electromagnetic properties of soils saturated with salt water and NAPL: Journal of Applied Geophysics, 52(4), 177-191.

Cardarelli E. and Di Filippo G., 2009, Electrical resistivity and induced polarization tomography in identifying the plume of chlorinated hydrocarbons in sedimentary formation: a case study in (Milan-Italy): Waste Management and Research, 27(6), 595602.

Colombano S., Davarzani H., Van Hullebusch E.D., Ignatiadis I., Huguenot D., Guyonnet D. 
and Deparis J., 2017, Drainage-imbibition tests and pumping of heavy chlorinated solvents in saturated porous media: measurements and modeling of the effects of thermal and chemical enhancement: 14th International AquaConSoil Conference-Sustainable Use and Management of Soil, Sediment and Water Resources.

Colombano S., Davarzani H., van Hullebusch E.D., Huguenot D., Guyonnet D., Deparis J. and Ignatiadis I., 2020, Thermal and chemical enhanced recovery of heavy chlorinated organic compounds in saturated porous media: 1D cell drainage-imbibition experiments: Science of The Total Environment, 135758.

Cosenza P., Ghorbani A., Florsch N. and Revil A., 2007, Effects of drying on the low-frequency electrical properties of Tournemire argillites: Pure and Applied Geophysics, 164(10), $2043-2066$.

Endres A. L. and Knight R., 1991, The effects of pore-scale fluid distribution on the physical properties of partially saturated tight sandstones: Journal of Applied Physics, 69(2), 10911098.

Endres A. and Knight R., 1992, A theoretical treatment of the effect of microscopic fluid distribution on the dielectric properties of partially saturated rocks: Geophysical Prospecting, 40(3), 307-324.

Endres A. and Redman J., 1993, Modeling the electrical properties of porous rocks and soils containing immiscible contaminants, Symposium on the Application of Geophysics to Engineering and Environmental Problems (SAGEEP): Environmental and Engineering Geophysical Society, Denver, Colo, 21-38.

Gharibi, M. and Bentley, L.R., 2005, Resolution of 3-D electrical resistivity images from inversions of 2-D orthogonal lines: Journal of Environmental and Engineering Geophysics, 10(4), 339-349. 
Glover P.W.J., Hole P.J. and Pous J., 2000, A modified Archie's law for two conducting phases: Earth and Planetary Science Letters, 180(3-4), 369-383.

Glover P.W., 2010, A generalized Archie's law for n phases: Geophysics 75(6), 247-265.

Griffiths D., 1999, Introduction to Electrodynamics (3rd edition ed.). Upper Saddle River, New Jersey: Prentice Hall. 286.

Grimm R.E. and Olhoeft G.R., 2004, Cross-hole complex resistivity survey for PCE at the SRS A-014 outfall: Symposium on the Application of Geophysics to Engineering and Environmental Problems (SAGEEP), Environmental and Engineering Geophysical Society (EEGS), 455-464.

Guéguen Y. and Palciauskas V., 1994, Introduction to the Physics of Rocks, Princeton University Press, Princeton, N. J.

Hashin Z. and Shtrikman S., 1962, A variational approach to the theory of effective magnetic permeability of multiphase materials: Journal of Applied Physics, 33(10), 3125-3131.

Hwang Y.K., Endres A.L., Piggott S.D. and Parker, B.L., 2008, Long-term ground penetrating radar monitoring of a small volume DNAPL release in a natural groundwater flow field: Journal of Contaminant Hydrology, 97(1-2), 1-12.

Iravani M. A., Deparis J., Davarzani H., Colombano S., Guérin R. and Maineult A., 2020, The influence of temperature on the dielectric permittivity and complex electrical resistivity of porous media saturated with DNAPLs: a laboratory study: Journal of Applied Geophysics, 172, 103921.

Jang, H., Park, S. and Kim, H.J., 2014, A simple inversion of induced-polarization data collected in the Haenam area of Korea: Journal of Geophysics and Engineering, 11(1), 015011. 
Jougnot D., Ghorbani A., Revil A., Leroy P. and Cosenza P., 2010, Spectral induced polarization of partially saturated clay-rocks: A mechanistic approach: Geophysical Journal International, 180(1), 210-224.

Kaselow, A. and Shapiro, S.A., 2004, Stress sensitivity of elastic moduli and electrical resistivity in porous rocks: Journal of Geophysics and Engineering, 1(1), 1-11.

Kemna A., Binley A., Ramirez A. and Daily W., 2000, Complex resistivity tomography for environmental applications: Chemical Engineering Journal, 77(1-2), 11-18.

Kizito F., Campbell C.S., Campbell G.S., Cobos D.R., Teare B.L., Carter B. and Hopmans J.W., 2008, Frequency, electrical conductivity and temperature analysis of a low-cost capacitance soil moisture sensor: Journal of Hydrology, 352(3-4), 367-378.

Korvin J., 1982, Axiomatic characterization of the general mixture rules: Geoexploration, 19(4), 785-796.

Lichtenecker K. and Rother K., 1931, Die Herleitung des logaritmischen Mischungsgesetzes aus allgemeinen Prinzipien der stationaren Stromung: Physikalische Zeitschrift, 32, 256660.

Louge M. and Opie M., 1990, Measurements of the effective dielectric permittivity of suspensions: Powder Technology, 62(1), 85-94.

Luo M., Wood J.R. and Cathles L.M., 1994, Prediction of thermal conductivity in reservoir rocks using fabric theory: Journal of Applied Geophysics, 32(4), 321-334.

Maineult A., Bernabé Y. and Ackerer P., 2004, Electrical response of flow, diffusion, and advection in a laboratory sand box: Vadose Zone Journal, 3(4), 1180-1192.

Maineult A., Jougnot D. and Revil A., 2018, Variations of petrophysical properties and spectral induced polarization in response to drainage and imbibition: a study on a correlated 
random tube network: Geophysical Journal International, 212(2), 1398-1411.

537

Mavko G., Mukerji T. and Dvorkin J., 1998, The rock physics handbook: Tools for seismic analysis, in Porous Media. Cambridge University Press, New York.

Mashhadi, S.R. and Ramazi, H., 2018, The application of resistivity and induced polarization methods in identification of skarn alteration haloes: A case study in the QaleAlimoradkhan Area: Journal of Environmental and Engineering Geophysics, 23(3), 363368.

Mendelson K.S. and Cohen M.H., 1982, The effect of grain anisotropy on the electrical properties of sedimentary rocks: Geophysics, 47(2), 257-263.

Orlando L. and Palladini L., 2019, Time-lapse laboratory tests to monitor multiple phases of DNAPL in a porous medium: Near Surface Geophysics, 17(1), 55-68.

Pankow J.F. and Cherry J.A., 1996, Dense Chlorinated Solvents and Other DNAPLs in Groundwater, History, Behavior, and Remediation. Waterloo Press.

Persson M. and Berndtsson R., 2002, Measuring nonaqueous phase liquid saturation in soil using time domain reflectometry: Water Resources Research, 38(5), 22-1-22-8.

Philippe N., Davarzani H., Colombano S., Dierick M., Klein P.Y. and Marcoux M., 2020, Experimental study of the temperature effect on two-phase flow properties in highly permeable porous media: Application to the remediation of dense non-aqueous phase liquids (DNAPLs) in polluted soil: Advances in Water Resources, 146, 103783.

Revil A., Binley A., Mejus L. and Kessouri P., 2015, Predicting permeability from the characteristic relaxation time and intrinsic formation factor of complex conductivity spectra: Water Resources Research, 51(8), 6672-6700.

Rocha M.D.S. and Simões-Moreira J.R., 2005, A simple impedance method for determining 
ethanol and regular gasoline mixtures mass contents: Fuel, 84(4), 447-452.

560

561

562

563

564

565

566

567

568

569

570

571

572

573

574

575

576

577

578

579

580

Rodriguez A. and Abreu R., 1990, A mixing law to model the dielectric properties of porous media: In SPE Latin America Petroleum Engineering Conference. Society of Petroleum Engineers.

Romig P., 2000, Seeing Into the Earth: Noninvasive Characterization of the Shallow Subsurface for Environmental and Engineering Application: National Academies Press, Washington D.C.

Roth K., Schulin R., Fluhler H. and Attinger W., 1990, Calibration of time domain reflectometry for water content measurement using a composite dielectric approach: Water Resources Research, 26, 2267- 2273.

Santamarina J. and Fam M., 1997, Dielectric permittivity of soils mixed with organic and inorganic fluids: Journal of Environmental and Engineering Geophysics, 2, 37- 51.

Schilling F., Partzsch G. M., Brasse H. and Schwartz G., 1997, Partial melting below the magmatic arc in the central Andes deduced from geoelectric field experiments and laboratory data: Physics of the Earth and Planetary Interiors, 103(1-2), 17-31.

Schmutz M., Blondel A. and Revil A., 2012, Saturation dependence of the quadrature conductivity of oil-bearing sands: Geophysical Research Letters, 39, L03402.

Schweitzer P.A., 2004, Corrosion resistance tables: metals, nonmetals, coatings, mortars, plastics, elastomers and linings, and fabrics. CRC Press.

Sen P.N., Scala C. and Cohen M.H., 1981, Self similar model for sedimentary rocks with application to the dielectric constant of fused glass beads: Geophysics, 46(5), 781-795.

Slater L., Barrash W., Montrey J. and Binley A., 2014, Electrical-hydraulic relationships observed for unconsolidated sediments in the presence of a cobble framework: Water 
583

584

Snieder R., Hubbard S., Haney M., Bawden G., Hatchell P., Revil A. and DOE Geophysical Moninitoring Working Group, 2007, Advanced noninvasive geophysical monitoring techniques: Annual Review of Earth and Planetary Sciences, 35, 653-683.

Sogade J.A., Scira-Scappuzzo F., Vichabian Y., Shi W., Rodi W., Lesmes D.P. and Morgan F.D., 2006, Induced-polarization detection and mapping of contaminant plumes: Geophysics, 71(3), B75-B84.

Somerton W.H., 1992, Thermal properties and temperature-related behavior of rock/fluid systems. Elsevier.

Tiab D. and Donaldson E. C., 2004, Theory and practice of measuring reservoir rock and fluid transport properties: Petrophysics, Gulf Publishing Company.

Titov K., Kemna A., Tarasov A. and Vereecken H., 2004, Induced polarization of unsaturated sands determined through time domain measurements: Vadose Zone Journal, 3(4), 11601168.

Tsonos C., 2019, Comments on frequency dependent AC conductivity in polymeric materials at low frequency regime: Current Applied Physics, 19(4), 491-497.

Waff H.S., 1974, Theoretical consideration of electrical conductivity in a partially molten mantle and implications for geothermometry: Journal of Geophysical Research, 79(26), $4003-4010$.

Weller A., Nordsiek S. and Debschutz W., 2010, Estimating permeability of sandstone samples by nuclear magnetic resonance and spectral-induced polarization: Geophysics, 75(6), E215-E226.

Wharton R.P., Rau R.N. and Best D.L., 1980, Electromagnetic propagation logging: Advances 

Society of Petroleum Engineers.

607 


\section{Figure captions}

609

610

Figure 1: Scheme of a) a vertical cross section of a cell and b) the experimental setup.

611

Figure 2: SIP response of resistivity and phase spectra of samples with ( $a$ and b) CT+water and

612 (c and d) $\mathrm{CO}+\mathrm{SE}$ as a function of saturation change, for the first drainage.

613

Figure 3: Time series of SIP responses of cells with a and b) for resistivity and phase of

614 $\mathrm{CT} /$ water and c) resistivity of $\mathrm{CO} / \mathrm{SE}$ at $\mathrm{f}=1.46 \mathrm{~Hz}$.

615

Figure 4: Correlation curves of relative permittivity and (a) water saturation and (b) SE

616 saturation fitted by the CRIM model. Yellow point: beginning of the experiment (beginning of

617 the first drainage), red point: residual saturation, and black point: irreducible saturation.

618

Figure 5: Correlation curves of resistivity and (a) water saturation and (b) SE saturation fitted by generalized Archie's law. Yellow point: beginning of the experiment (beginning of the first drainage), red point: residual saturation, and black point: irreducible saturation.

621

Figure 6: Phase as a function of water saturation (with linear fitting) at $1.46 \mathrm{~Hz}$.

622

623

624

625

626

627

628

629

630

631

632 
a

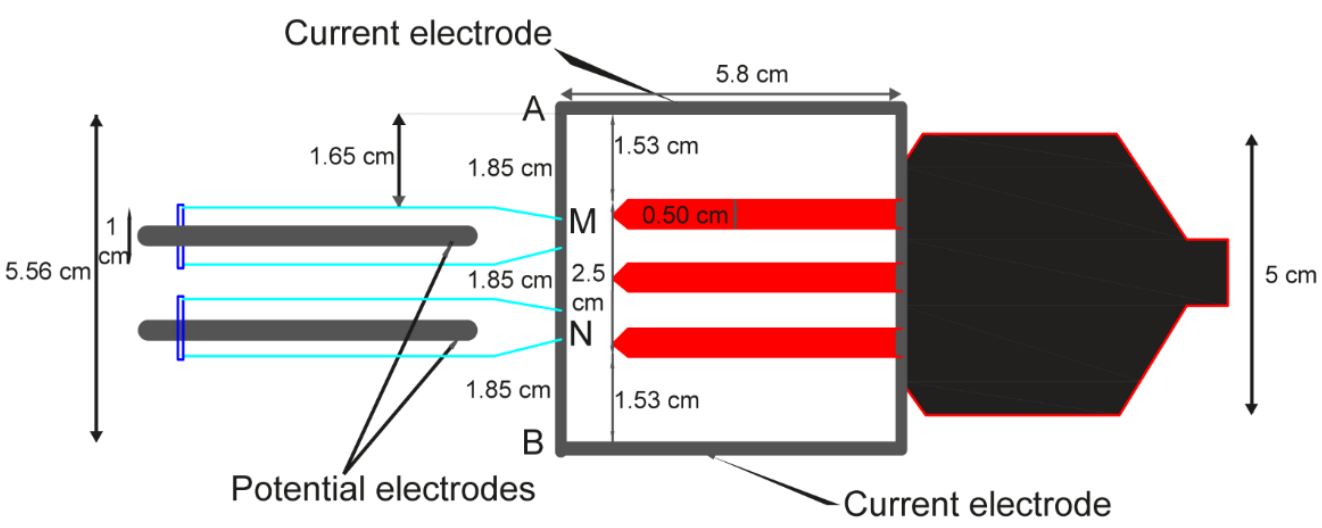

b

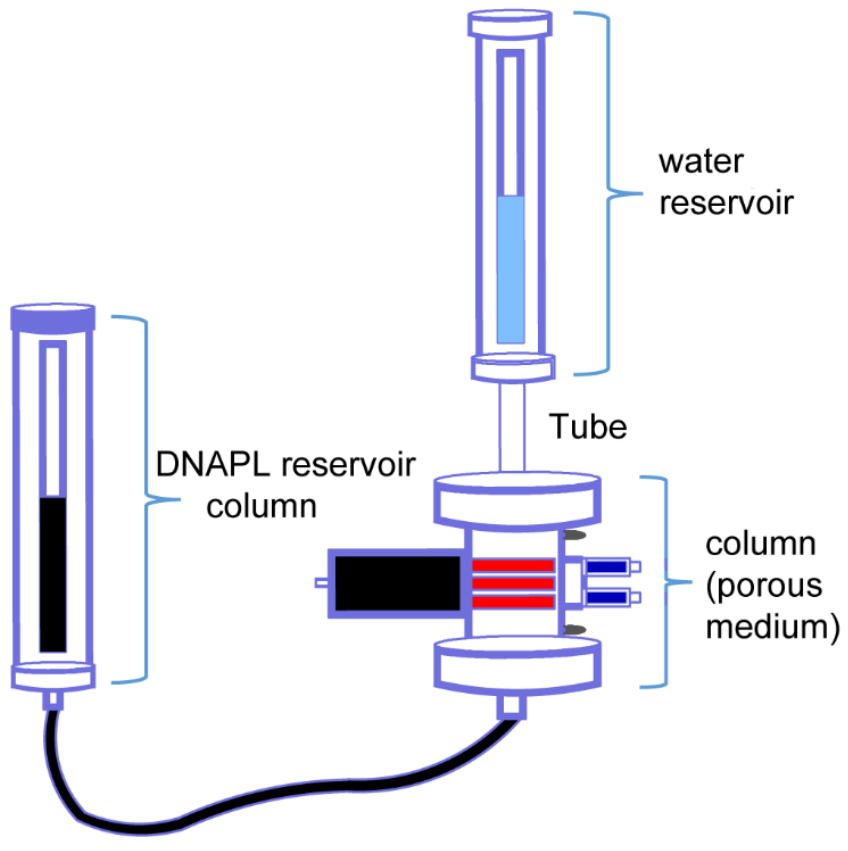


Figure 2
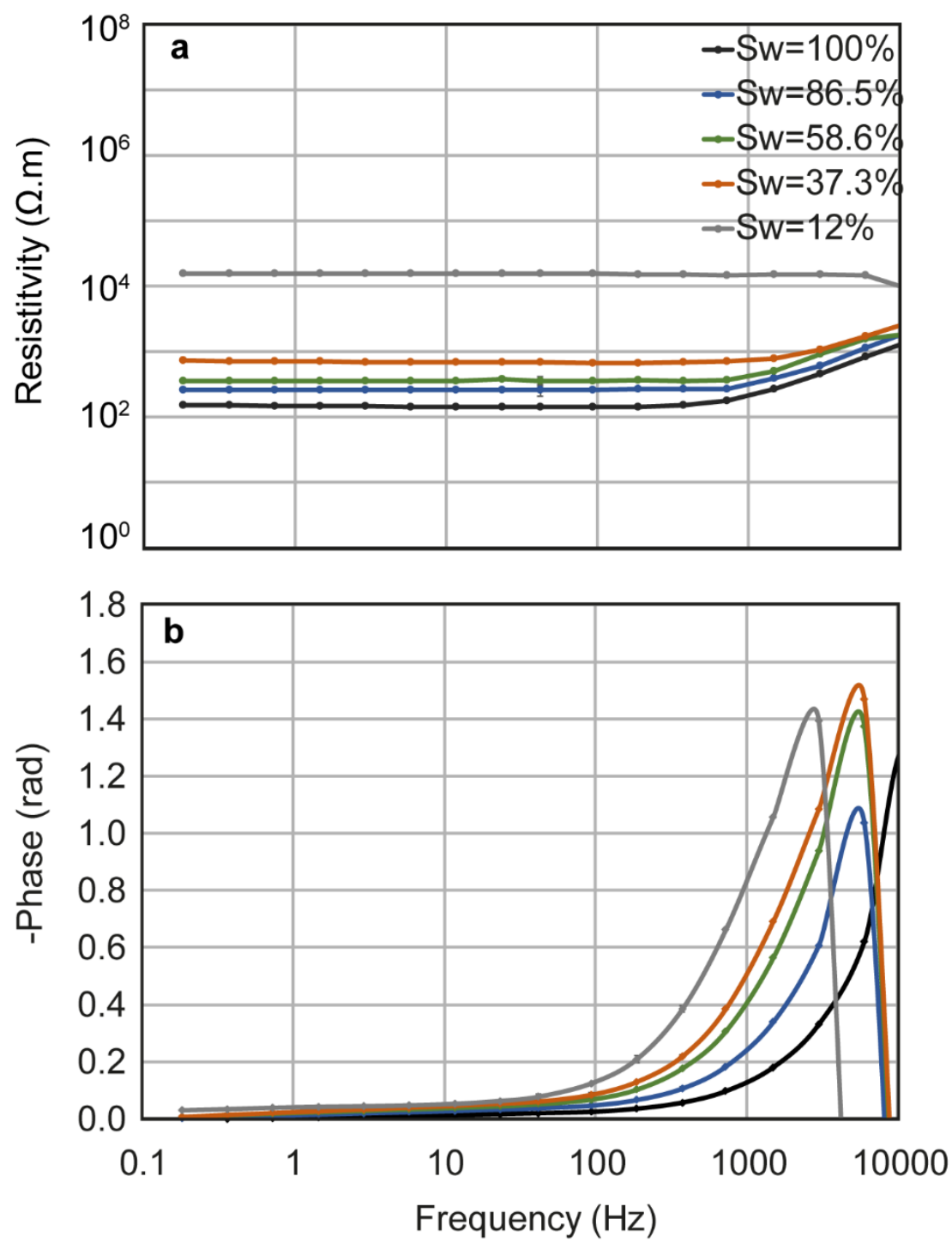

637 

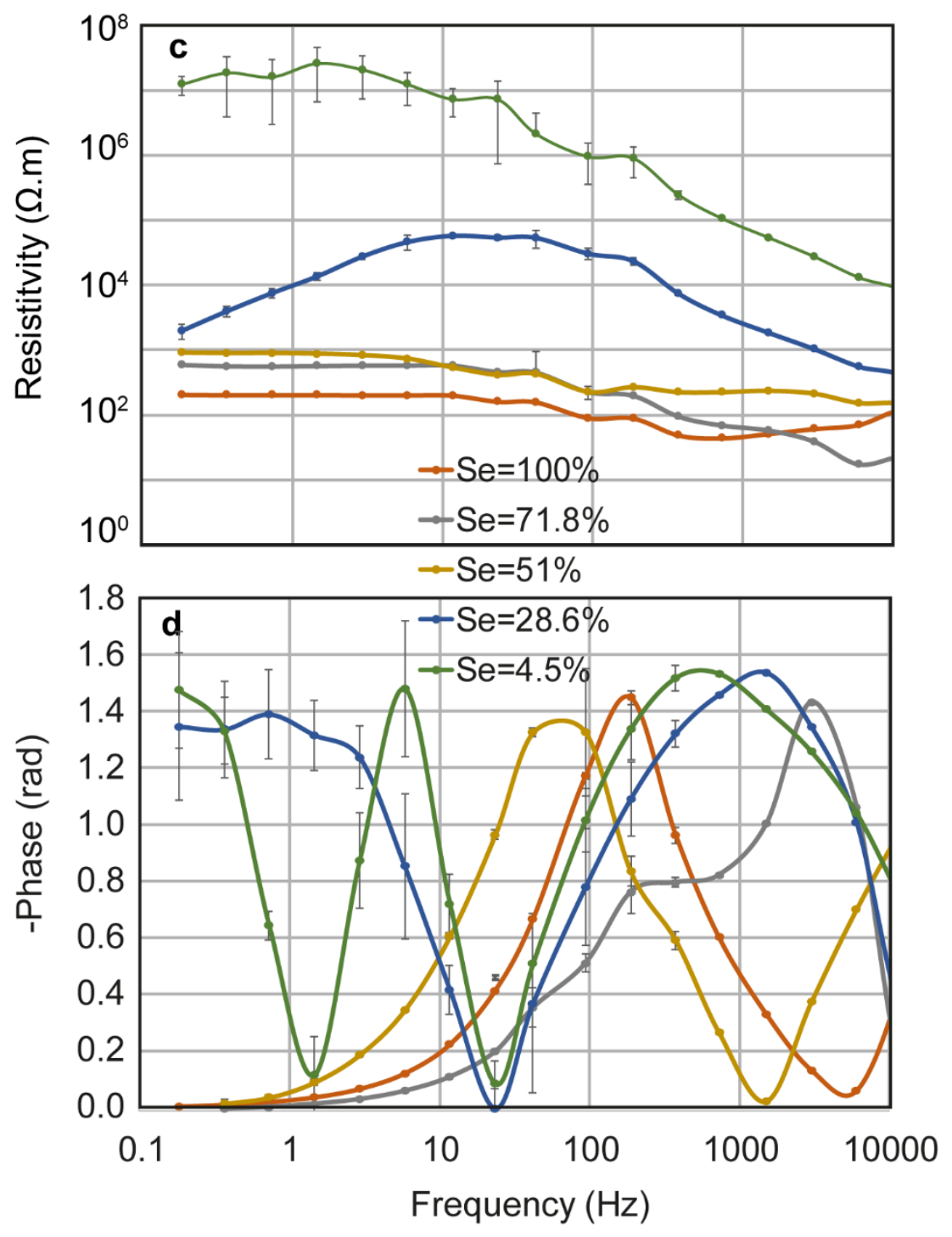

639

640 

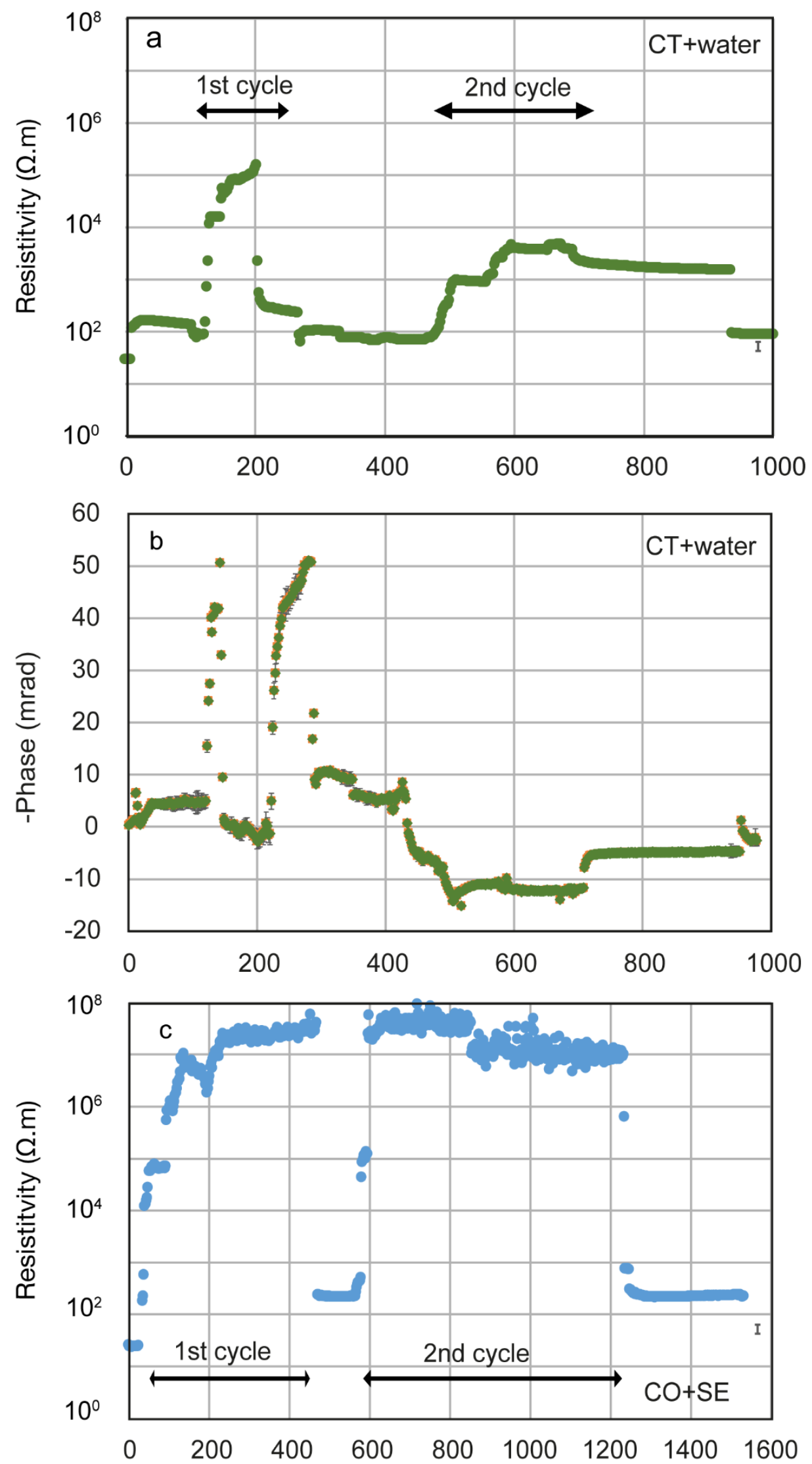

Time (hours) 


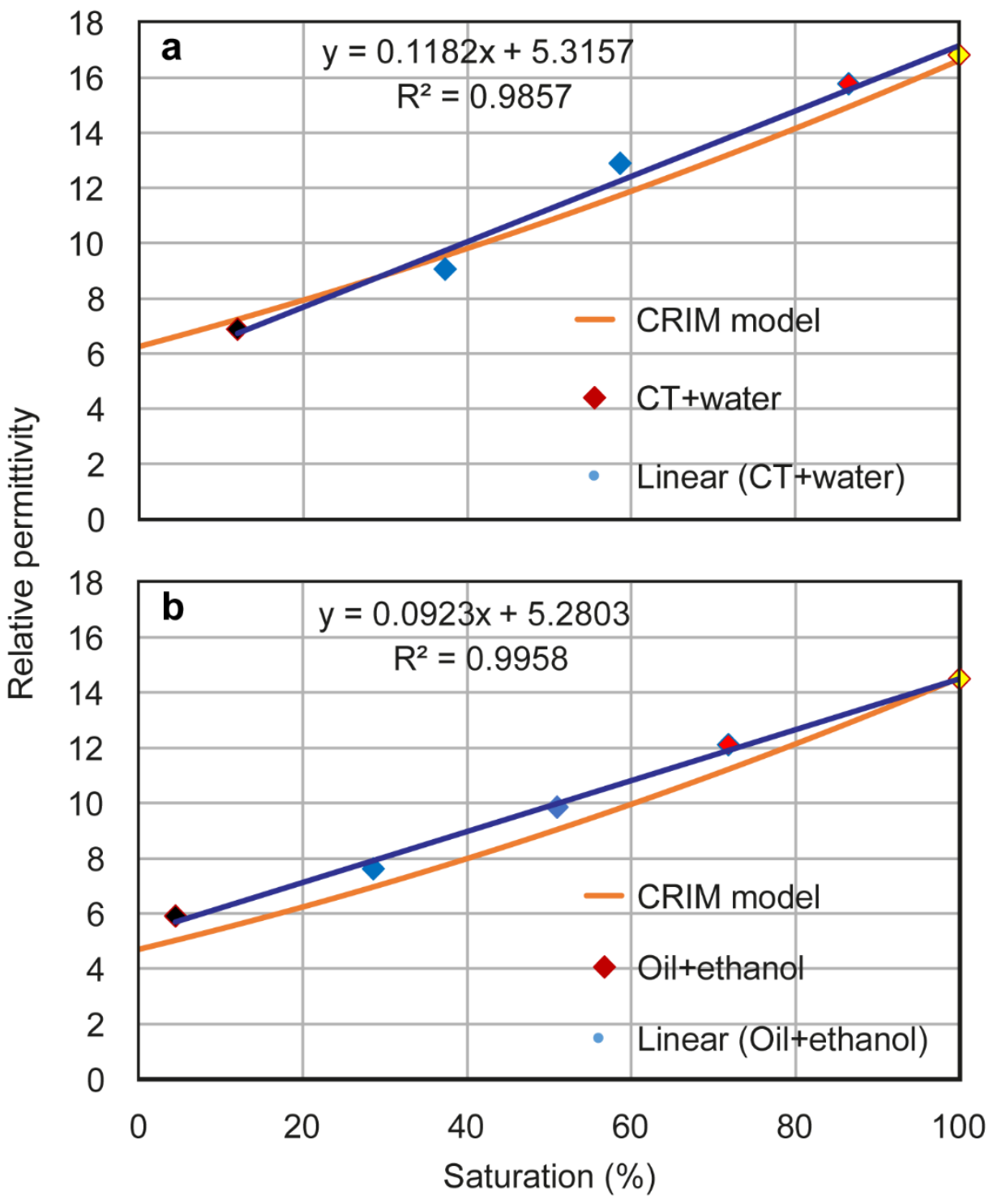

645 


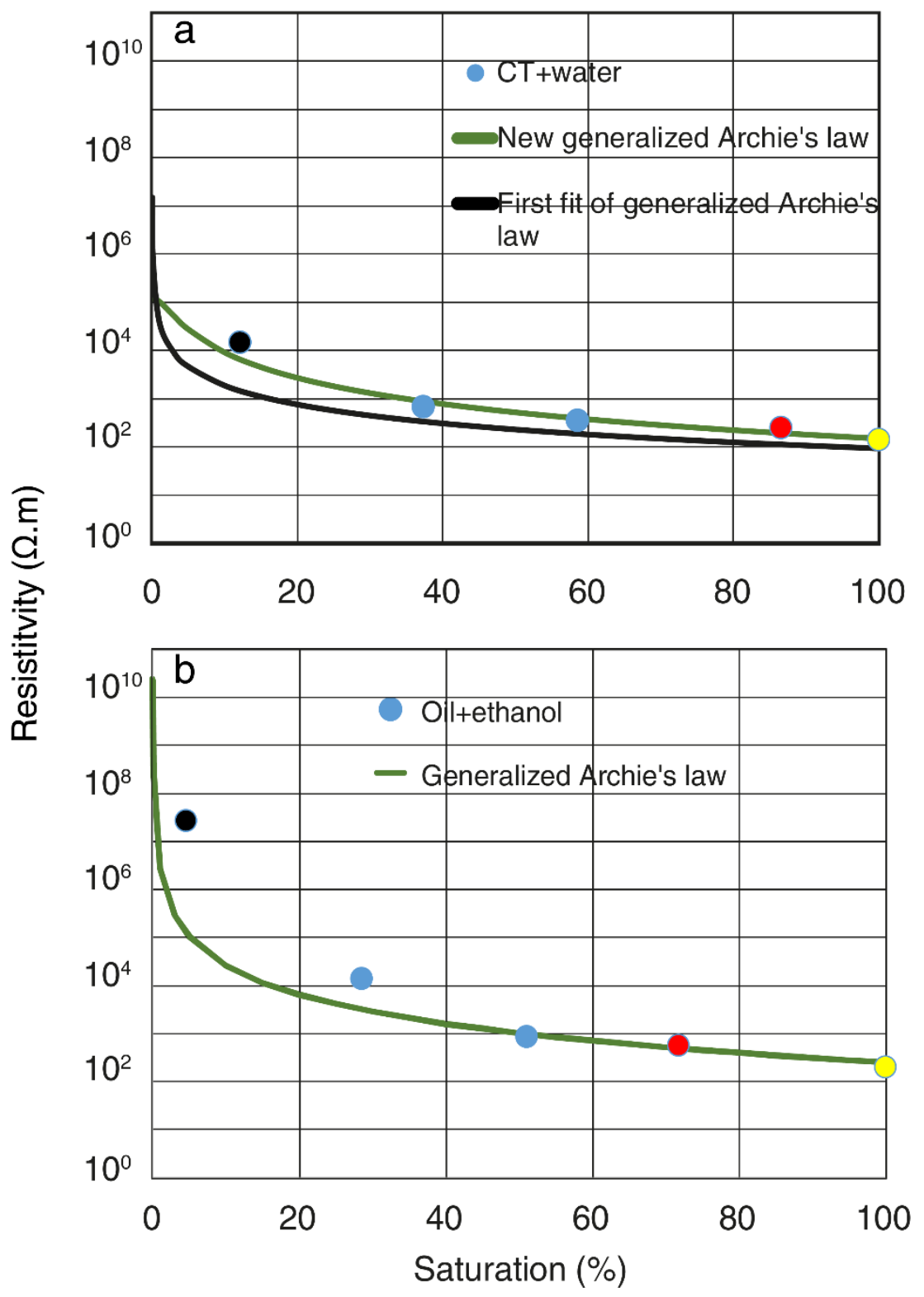

649 


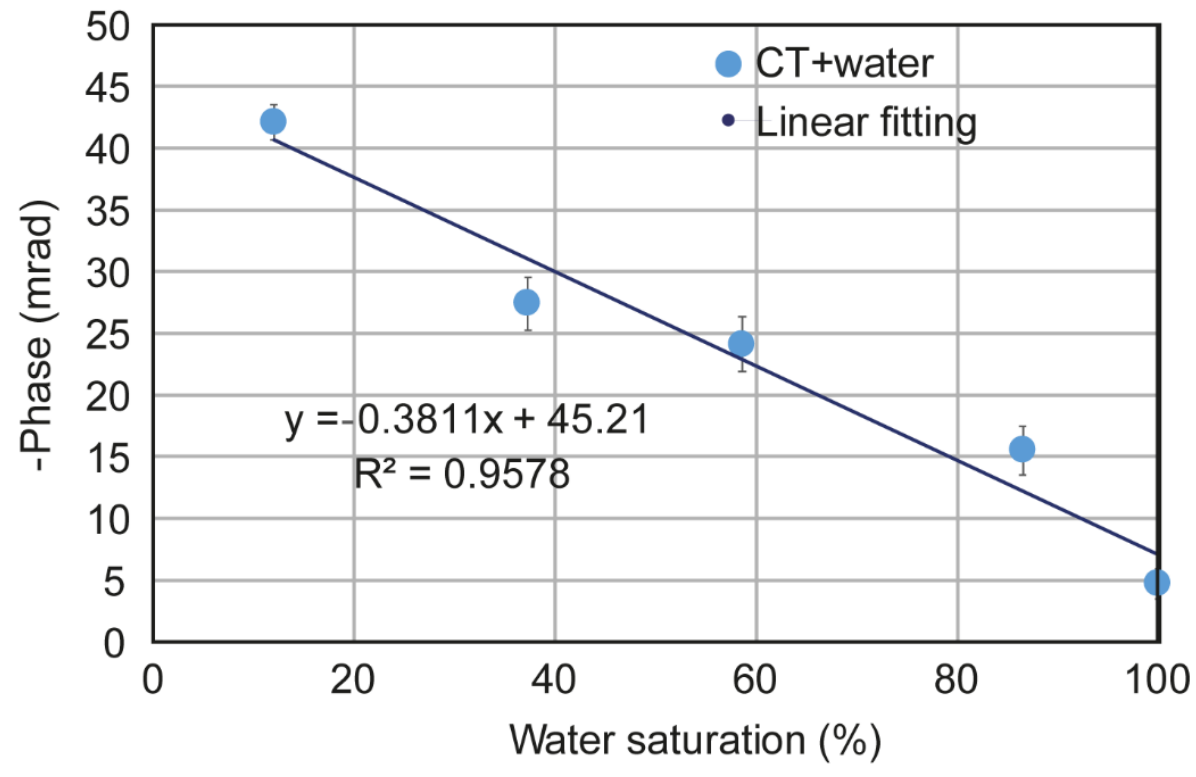

652 